\title{
1. Organizing a global world
}

It seems as if the world is becoming increasingly borderless. Products, organizations and services are becoming more and more global in nature, buying products made outside the buyer's immediate environment has become commonplace, and organizations that operate all over the world are becoming the norm. The line between local and global is becoming less distinct, as the borderless world expands, opening the way for a range of product offerings and job opportunities. Few people in the West can picture a world without these global streams of impressions, images, things, products and relationships that flow through our everyday lives.

But globalization also raises questions. Several aspects of products and their production complicate matters and create uncertainty among consumers. It is often difficult to find out how a product is made or whether it poses risks to safety, health, or to the environment. Is this a good product? Will it last? Was child labor used in its production? Are the products safe to use?

Given globalization, a buyer often has no way of asking the producer these questions, since the distances may be great and production sites located far from the consumer. A product may be made in one country, packaged in another, imported to a third country, then sold in yet another. Products and product information are, in addition, becoming increasingly complex. Many are composed of numerous different parts transported back and forth across borders before finally being assembled and sold to someone, somewhere in the world. Making a purchase today can therefore be fraught with uncertainty about the product's manufacture, risks, and characteristics.

This raises a problem. As consumers, we all want to be as certain as we can that the products that we buy are safe, of good quality, and sustainable. At the same time, it is unrealistic to expect each buyer to track each and every part that goes into a product, as well as to monitor and control its production, risks, and product characteristics. One way to reduce this uncertainty is to have someone else separate the good products from the less good, to let others conduct the controls for us. The problems of uncertainty caused by globalization set the stage for a new actor to enter: the third party. 


\section{AN 'OTHER'}

How to organize such third parties varies across countries and over time. But either way, such uncertainty-reducing third parties should preferably have a degree of authority that instils confidence and trust - someone we can trust other than ourselves. In the past, one common solution for distinguishing good products from bad was for the state to serve as the third party. Using Sweden as a case in point, up until the 1990s, the Swedish state monitored and controlled a large number of products, production facilities and organizations. Its task was to safeguard the public good, to provide a guarantee that products did not pose risks to safety, health, or property. Control of products and production facilities was thereby a responsibility that was assigned to the public sector and was not to be managed by commercial enterprises driven by profit. State regulations set out what should be under state control and how the controls should be carried out.

In Sweden, being a country where citizens traditionally have a relatively high confidence in the state's conduct, the state has often served as an 'other,' the third party. State organizations conducted controls on behalf of the country's citizens when citizens were unable to carry out these controls themselves. State monitoring and control is often called 'surveillance' and is something that is taken for granted in society today - that schools, care facilities, workplaces, the gambling market, agriculture, the food sector, and public health are working as they should. What is being put under state surveillance is ultimately a political question - in some countries state surveillance covers a larger number of sectors than in others.

State surveillance also means that parliaments and governments have been responsible for the monitoring and controls carried out. Just as in other sectors where parliament legislates and government governs, surveillance and control form part of a democratic chain of clear command and assignment of accountability. Politicians have thus borne the ultimate responsibility for these control activities.

But big changes have taken place in society since the 1980s. The state is no longer seen as the self-evident 'other' to conduct controls on behalf of the country's citizens. One such changed view of the state's role as a controlling third party relates to substantial changes in how the public sector is organized. Marketization processes (where activities are expected to operate according to a logic of competition) and privatization processes (where public operations are sold and turned into companies or corporations) have reshaped the roles and tasks of public authorities. Companies are, to an increasing extent, now performing tasks that were once performed by public bodies, a process that is sometimes labeled 'NPM' (New Public Management). 
Who can, may or should be this third party is also influenced by the fact that people now travel, work and consume across borders. Globalization constitutes an obstacle to carrying out state control as it used to be carried out. National authorities do not have the ability to conduct controls in other countries and on other continents. More and more trade also occurs online, rendering physical and territorial boundaries even more difficult to maintain.

The role of the state is changing, globalization is increasing, and products and production processes are becoming more and more complex. Higher and higher demands are also being placed on products and manufacturing. Other aspects on production processes such as work environment, health, human rights, quality and efficiency are also expanding, placing new requirements on a growing number of organizations, regardless of where the products are being made or the services being sold.

But as our surroundings change, the need for control does not appear to be falling; rather, it appears to be rising. The larger the world around us becomes through globalization, the greater the need for an 'other,' a third party to monitor and control on behalf of citizens and consumers. And if the state is no longer going to be that 'other' - who, then, will be?

One option would be to create a giant global super-organization that monitors and controls all of the world's products. A worldwide 'other.' Such an organization, a power above all powers, could establish the rules for how controls should be carried out, and then itself ensure that these rules are followed. This would mean that all products and production in the world would be monitored and controlled by the same organization, according to the same rules. But it is unclear where such an organization would be situated and who would make the decisions in that organization. It is also unclear what relationship the global organization would have to national governments. There is little incentive for all of the world's product companies to fall in line under a single regulatory organization. An organization of such proportions would likely end up becoming either Orwellian in power or watered down and ineffectual.

Another alternative would be to dispense completely with the third party and have, instead, consumers buy only things that they themselves can assess - by seeing, touching, smelling, and trying them out - with no third-party rules and controls. Quite the opposite of a global super-organization in charge of everything. Consumers would buy products where they are produced, a scenario that reduces uncertainty through local production and direct personal contact. This would negate the need for common rules for monitoring and control, since consumers themselves would decide what is good and what is not. Making purchases in such a situation would be time-consuming, however, as every product would need to undergo the consumer's own sensory controls, which in turn would require that, for every product purchased, buyers would 
have to make their way to where the product is produced to meet the person who made it. In today's society, few consumers have time for this.

In this book I examine one system that has emerged to control products and organizations, a system with rules for how controls should be carried out and for how products should be designed and work. Millions of organizations follow these rules so that their products and activities can be compared and coordinated, and thousands of organizations are working to ensure that the rules are followed. In the book I call this system a 'global control regime,' a regime being a control system, an order built specifically to govern.

The global control regime has been created to control people, organizations, and products. In this regime, the 'other' is not an authority of the local state but a certification company operating on a market, and the rules used to control are not established by the local parliament, but standards set by international standardization organizations. Over the past 30 years, the global control regime has grown and become nested in both the private and public sectors; a development that has occurred in silence, without debate - in research, politics, or the media - despite the fact that the global control regime affects the work of companies, state authorities and consumers every day. Expansion of the control regime has meant a change in who might be assigned responsibility and who governs. Most people today, however, know little about how the global control regime is constructed, how it came to be, who is in charge, and who is responsible. For this reason, this book sets out to uncover the global control regime.

\section{STANDARDS, CERTIFICATION AND ACCREDITATION}

In the global control regime, international standards are used to regulate products and organizations. Creating a standard means creating a rule for measures, dimensions or terminology for something, a common vocabulary to standardize and make things comparable. Related concepts include formalization, quantification, routinization, evaluation, classification, rationalization, and objectification (Timmermans and Epstein 2010) - processes that enable standardization, coordination and governance. Creating a society with a functioning road system, measurement and weight system, and systems for population registry, registration of ownership, employment and wages, pretty much all aspects of an organized society, has to do with standardizing and coordinating things to allow them to be governed from a central location (Scott 1998).

In the context of monitoring and control of products and organizations, the term standard has been assigned a specific meaning. A standard is a rule that specifies how a control should be carried out, how a product should be designed, or how an organization should be organized. Once established, 
standards have a curious tendency to become invisible and work unseen in the background, sinking below the visible surface (Timmermans and Epstein 2010), often going unnoticed until they are missing, like when a European plug doesn't fit an American outlet.

Standards are created by standardization organizations. A set of committees with different tasks form the basic internal structure of the standardization organizations. A majority of the representatives on the committees come from industry, a smaller part from public authorities or civil society organizations. Together, committee members come up with the standards. A standard is thus the result of discussions and compromises met in the committee work of these standard-setting organizations (Tamm Hallström 2000).

The initial need for a standard often stems from a need to coordinate industrial production between countries (Tamm Hallström 2000; Erlingsdottir and Lindberg 2005), for example, the need for a bolt produced in one country to fit a nut produced in another. But standards are also used in a growing number of areas - everything from tools and machinery to work environments, human rights, and sustainable fishing practices. Since the post-war era, the development of standards, or the 'world of standards' as Brunsson and Jacobsson (2000) called it, has increased in scope:

When things don't work as they should, it often means that standards are absent. But when ISO-standards are applied, life is just so much richer.

The above quote is taken from an ISO (International Organization for Standardization) video advertisement. At the end of the video ad, the ISO logo appears, the form of which resembles the earth's globe, not unlike the UN logo. The ISO is the world's largest standard-setting organization and creator of the ISO standards used around the globe. The most widely spread of these is the ISO 9001 quality standard, a standard for management systems. ISO 9001 specifies how an organization should establish administrative processes and routines for its day-to-day activities. These processes and routines are documented and written down, according to the standard.

In this context the verb standardizing means establishing a standard to be followed. Following a standard is usually voluntary and in this way standards differ from legal statutes or directives (Brunsson and Jacobsson 2000). As opposed to statutory law, a standard is also something that is purchased. For example, the ISO 9001 comes at a cost of approximately 150 USD and is issued as a PDF file upon payment.

International standards are often presented, in research and in practice, as an answer to the questions raised by globalization. Standards constitute a clear expression of a global order and rationalization (Drori, Jang and Meyer 2006). Standards, such as ISO standards, thus constitute a set of common international 
rules that organizations follow. An increasing amount of the regulatory work earlier handled by nations and states, is now handled by private-law international standards organizations like the ISO or their European equivalents CENELEC (European Committee for Electrotechnical Standardization) or CEN (European Committee for Standardization), and then most often translated and distributed by a national standardization organization. Standardization organizations can be found in a growing number of countries and form an infrastructure that spans the world (Tamm Hallström 2000). The worldwide infrastructure means that the standards apply in a greater number of countries than if they had been set by national parliaments. This is one of the elements symbolized by the ISO globe.

Guillet de Monthoux (1981) described standards organizations as 'rationalization associations,' and the vastly growing standardization as an expression of people's insatiable need to be assured of something, be it safety, quality or just the assurance as such. Standards are intended to create a guarantee of a rational and safe society. They make up a skeletal framework, an infrastructure for a global governance regime, but offer no guarantee that the regime will work. Despite the increased use of standards around the world, the problem of uncertainty remains - we have no way of knowing whether a standard is being followed or not. In fact, a reasonable question would be - why would organizations follow standards at all, if they are voluntary and cost money?

\section{A THIRD PARTY - CERTIFICATION ORGANIZATIONS}

In order to ensure that standards are being followed, a third party has been created - namely, certification organizations. It is thus no longer the state, but the certification organizations who are supposed to install trust in products and organizations. Certification is carried out by various certification companies and costs money. It is the organization being certified who bears this cost.

People, products and organizations may become certified. We see the traces of this proliferating control activity through the little signs the certification firms leave behind: logotypes and stamps ensuring that this specific organization or product has passed a control - the Rainforest alliance frog on chocolate bars or the ISO 9001 diploma at the dry cleaners or at the dentist. These logotypes are images aimed to simplify the complexity of a product or organization in order for consumers, customers or citizens to reduce their uncertainty about that product or organization.

We see these logotypes and signs on an increasing number of places because certification is spreading. In 2017, 1.5 million organizations were certified according to ISO standards for management systems (ISO Survey 2017). This means that 1.5 million organizations documented their work routines and showed this documentation to a certification auditor who in turn checked the 
organization's work against the ISO standard - a costly process in terms of both time and money.

Because it is carried out according to international standards, certification is an international phenomenon in the sense that what it signifies is understood across national borders. This means that a dry cleaner in Nairobi may be certified by the same company as a dentist on the outskirts of Stockholm. Some researchers (Conroy 2007; Bartley 2011; Marx 2011) see the advance of certification as a revolution of sorts. Others (Bromley and Meyer 2015) see it is as a move toward a hyper-organized society.

\section{A LESSER-KNOWN FOURTH PARTY - THE ACCREDITATION ORGANIZATION}

In order for a third party to serve its function, one must be able to trust that third party, since it is the third party who makes decisions for us when we, the consumers, don't have the option of direct contact with the producer. While it is true that third-party certification organizations leave a trail after them in the form of labels, symbols and logotypes, to guide consumers and reduce uncertainty, we have no direct contact with the certification company either. As consumers, we are once again left with uncertainty - with no way of knowing whether certification companies are properly controlling if manufacturers are following standards, no way of knowing that certification companies are not being paid to issue certificates without actually setting foot on production sites, and no way of knowing that certification companies are not helping manufacturers to slip through without actually meeting the standards. In other words, certification does not really solve the initial problem of uncertainty.

To handle this unsolved problem of uncertainty, the global control regime has created a fourth party, called 'accreditation.' Accreditation is performed by accreditation organizations, which may be companies or public authorities. Accreditation becomes a control of the controller, a certification of the certifier. Unlike certification, however, accreditation leaves no clear traces for the consumer to see. This may be why the fourth party remains largely unknown, among researchers and practitioners alike. One of the aims of this book is to describe and understand the role of accreditation in relation to standards and certification. Given that accreditation often is constructed as a public task, understanding accreditation also becomes a way of understanding the changing role and function of the state in a global society. 


\section{ORGANIZING, ORGANIZATIONS, AND THE MEANING OF 'MACRO-ORGANIZATION'}

What I have begun to describe here is a complex global web of standards, standards for standards, control of standards, control of control, and control of the control of control. This vast webbed system appears to be comprised of a large number of organizations that, in different ways, establish the rules, govern, coordinate, and control one another: standards organizations, certification organizations, accreditation organizations, and producers of goods and services. The system is constructed in such a way that it somehow - although spread out all over the world, populated by thousands of organizations - holds together. How?

Organization theory has long inquired about how organizations create coordination and control. Early on, Fayol (1916/2008) and Weber (1922/1983) presented principles of organization and bureaucracy as composed of formalization, coordination, control, authority, regulation and division of labor. In the 1960s, theories of organization gained ground, and the organization as an entity became organization theory's primary unit of analysis (for a detailed description, see Starbuck 2003; Czarniawska 2013): the so-called 'formal organization.' The concept of the formal organization then led to investigations of the organization's environment. Perrow (1986) and Powell and DiMaggio (1991) claimed that organizations are surrounded by other organizations. Concepts such as the 'institutional environment' made up of rationalized rituals (Meyer and Rowan 1977) have been used to understand how organizations adapt and relate to their environment, and the environment has been analysed based on notions of conflicting institutional logics (Friedland and Alford 1991).

In large parts of organization theory, there is an assumption that organizations are influenced, shaped by and adapt to their surrounding environment, a perspective that originated from biology, and inspired by systems theory (Czarniawska 2013). The organization is thereby also assumed to be something separate from its environment (Ahrne, Brunsson and Seidl 2016), something ontologically different.

The global control regime is built by organizations that are organized in a specific way. The regime is thus not a formal organization, but is made up of organizations that organize one another and that together form a complex order. To understand how this order is constructed requires that we widen the scope on organizing, and not reserve it as an activity that takes place only within organizations. Orders created among organizations must also be understood as organized - controlled, coordinated, governed and regulated. In this book I take an interest in organization theory research that seeks to describe and explain the organizing of, among and outside organizations (Ahrne and 
Brunsson 2011, 2019; Czarniawska 2013; Ahrne, Brunsson and Seidl 2016). The imagined line separating organizations and their environment is not a clear or fixed one, but is instead blurred, penetrable, and in constant transformation: the control regime's order is comprised of organization within, among, outside, and of organizations. The organization created by standards, certification and accreditation, leads to what I describe as 'macro-organization' (see Brunsson, Gustafsson and Tamm-Hallström 2018). In using this term, I put forward a general organization theory argument - that organization as a state of order can be created also among organizations and that organization theory should seek to understand this form of organization through concepts taken from the formal organization and not from its surrounding environment. The theoretical arguments on macro-organization constitute the first contribution of the book, and are elaborated in Chapter 9. Macro-organization is an exceedingly well-organized order that in many ways resembles the formal organization. Just as in the case of the formal organization, macro-organization contains a rationalized hierarchy that builds on rules and documentation, a well-developed division of labor, specialization, coordination, a hierarchy, and centralization. But macro-organization also differs on a number of important points. Macro-organization is built on a large set of formal organizations and organizing efforts between them. As a whole, however, macro-organization has no head - no sovereign, no king, no regent, no boss - no-one in charge with absolute power to decide over all of the participants. Neither is there a rule that, like a constitution, applies for all its parts. This means that macro-organization is an organizational phenomenon in which it is unclear who governs.

\section{WHO GOVERNS?}

Previous research on certification and standards has stressed the non-state, market-like characteristics of these activities: certification and standard-setting have been presented as private-law, international, non-state tools for regulation and control in a global world. Concepts such as non-state market regulation (Marx 2008) or non-state market-driven governance (NSMD) (Bernstein and Cashore 2007) have been used. Standards and certification have also been called a 'social regulatory form' (Bartley 2011), to underline the fact that standards constitute 'soft law,' in contrast to 'hard' technical rules, in practice often national regulations or legislation. Concepts like system of governance (Bartley 2007) and hybrid fields of governance (Bartley 2011) have also been used to denote the kind of non-state, cross-border organizing that certification and standard-setting represent.

Accreditation is described as a coordinating of standards and certification (Fouilleux and Loconto 2016). Accreditation can be performed by state authorities (Gustafsson and Tamm Hallström 2018), meaning that when it 
is introduced the picture changes: the state appears to have a role to play in the governance regime, despite its market-like, private law nature. Because accreditation as a topic has escaped scholarly attention, we know very little about how this (often) public hub works in the commercial and market-like setting that standards and certification jointly constitute. Uncovering accreditation and showing how it enables global organizing, is the second contribution of the book.

The global control regime is a phenomenon that diffuses and spans borders. It spans the boundaries between organizations and their surrounding 'environment' as the regime is just as organized among its organizations as within them. The global control regime erases the distinction between local and global - its organizations use the same standards regardless of their location. The boundary between private and public also becomes reshaped. Both companies and authorities work in the control regime - companies follow state laws and authorities follow private-law standards.

But despite emphasizing the boundary-spanning, market-oriented and private-law nature of standardization and certification, previous research elucidates neither the shift that has occurred from public to private in the spread of standards and certification nor the consequences of this shift. Who is responsible for the standards being more and more widely used? Who is responsible for the controls carried out? Who governs authorities when the rules that guide their work come from extra-parliamentary organizations? And what authority do parliaments and governments have to govern given the changes exemplified by the control regime? These are questions that remain to be answered.

The control regime crosses boundaries because it is made up of a large number of standards and organizations organized such that they are held together in a single regime. There is thereby an assumption that the regime is able to govern because it is composed in a certain manner. All of these organizations would otherwise merely constitute a group of organizations. The overarching question in the book is: How was a global control regime constructed? By asking how it was (and not just how it is) constructed, I wish to capture the step-by-step process of how the control regime came to be. All of these organizations, controls and rules have not always been there, but developed over time and continue to grow.

To help answer this, I pose two sub-questions, the first being: What components were used to build the global control regime and how do these components fit together?

As noted above, the control regime is made up of several organizations organized in a way that seems to hold the control regime together and allows it to govern. In order to understand and explain how this occurred, I examine which organizations make up the control regime, what they do, who they control, who controls them, what the rules are and how these rules are linked to 
the different organizations. I call the various parts of the control regime - that together make up its construction - 'components.'

I described above how accreditation organizations represent a fourth party of the control regime. While accreditation may be invisible and remain, to most onlookers, unknown, it is also gaining influence in the control of certification, which should make accreditation a key component in the construction of the control regime. But despite accreditation's importance in the construction of a global control regime, and despite accreditation in many EU member countries constituting a part of the state administration, the body of research on the topic is very limited. It thereby constitutes an interesting area for research on public administration.

In order to understand the workings of accreditation, I also ask What role does accreditation play in the global control regime? The focus on accreditation may have to do with the role and responsibility of the state in a global world. Accreditation serves as a lens through which I am able to illustrate what a changing public sector can look like.

In order to study the construction of the global control regime, I needed to collect field data, and I needed a starting point. This starting point was Sweden in the 1970s. As a starting point, it serves as an illustration of how control and testing of products was carried out before the control regime came into being. It also serves as an illustration of how a public order was replaced by a global and mostly private one. The case of Sweden is used as a point of observation, I describe the changes happening in Europe over time, from a Swedish perspective. But as Sweden is a part of Europe, the general changes and reform ideas being presented in the field material are illustrative for other countries as well. As the global control regime emerges, the case of Sweden becomes less and less visible and the regime itself comes into focus.

\section{OUTLINE OF THE BOOK}

Following this introductory chapter, Chapter 2 presents a review of earlier research on standards and certification, as well as the small body of research on accreditation.

In Chapter 3, I place standards, certification and accreditation in a theoretical context. I develop my arguments regarding research on organizing within and among organizations, after which I present a framework that enables an analysis of the global control regime as a way of governing at a distance, as well as ideas on the organizing of and among organizations.

Chapters 4 and 5 present the data from my field study. Chapter 4 describes the organization of the testing and control that emerged in Europe and replaced many national testing systems, the so-called 'Global Approach' initiated by the European Union. The Global Approach comprises self-conducted control, 
certification, standards, market surveillance and accreditation. Chapter 5 describes the Goods Package, a reform of the Global Approach granting accreditation a central function. Chapter 5 closes with a description of the European and international organizations of accreditation that enabled the control regime to become global.

In Chapter 6, I study the components that make up the control regime and the juxtaposition of these components, basing my analysis on the framework presented in Chapter 3.

In Chapter 7, I discuss the analysis in relation to the notions of governing at a distance. I show that the control regime governs by blurring the line between controlling and being controlled - the controller and the controlled are often the same organization. In this way the control regime is also able to absorb distance.

In Chapter 8, I discuss my analysis, present my conclusions, and relate the results of the analysis to previous research on standards and certification, as well as discussing the consequences of the control regime with respect to the role and responsibility of the state.

In Chapter 9, I elaborate and extend the theoretical argument about organizing among organizations, by delving more deeply into the discussion of macro-organization. 